lays the foundation of what becomes habitual or instinctive. In man, unconscious thought becoming habitual, it is the nursery again of conscious thought, the two conditions in the adult coexisting.

Turning to comparative psychology, a branch which has always appeared to me of particular importance, we find in intelligent animals, as the dog, either in community (commonly called wild) or in the domesticated state, the same nature of mind as in man and the like manifestations. In the young animal, however, there must have been the same precedent stage, though the conscious stage is of course produced earlier than in man.

This raises the question, on which we can speculate, but which we cannot as yet solve, whether some animals are not mostly in the state of unconscious thought, never attaining to that of conscious thought. Looking to the cases of degradation in man, it appears to me that in softening of the brain the man falls back to the unconscious stage, and in some instances remains for some time in it, so that here we get an example of prolongation, it may he called continuance, of the unconscious stage.

Such a state as that of babitual unconscious thought may be regarded as possible and probable, and we are justified in applying it to many animals of inferior nervous organisation. The condition of consciousness being absent, the degree of pain is less, as must be the case in infants. So far from the saying of the master painter of mankind being true that the worm feels as great a pang as when the giant dies, the worm must be less sensitive and less sensible. It is quite possible that the antivivisectionists may be in the wrong as to lower animals, whatever reason they may have as to those like the dog.

There will be at least the like gradations of mind as of form in the animal world, and the difference between an animalcule and a dog will be enormous, and still greater that between the animalcule and man. In the higher stages the differences will be vastly augmented by the agencies at work. Thus it must be that the conscious stage producing precision of action influences the habitual condition of the unconscious stage. Having applied this to man, we may better conceive it, and form some notion of its prodigious relative development by considering how man so constituted has his power of thought enhanced by the great instrument of speech.

These causes contribute to the great differences which I long since pointed out between the rapidity of thought of one man and another, or of the same man at different times of life or under various conditions. My paper "On the Geographical Distribution of Intellectual Faculties in England," following one at the British Association, being published in the Fournal of the Statistical Society (June, I87I, p. 357), has escaped the notice of psychologists and physiologists, being esteemed statistical, whereas it is also psychological. At p. $357 \mathrm{I}$ gave an account of an experiment, showing a fluctuation in conscious thought in one adult of from $I$ to 4 , or 100 to 400 , denoting an enormous difference, and illustrative of the variations in mental power which exist in society. If, however, we were to estimate a child of 14 at 50 , then the ratio would be as $\mathrm{I}$ to 8 . If we take a child of 7 at the quarter of an adult, then we should have $I$ to 16. These are not extreme measures, for in the babe we may find I to $100, I$ to $200, x$ to 400 .

This is given as an illustration of what must exist in the animal world as to conscious thought, and that without reference to unconscious thought, which must be the condition of many classes. Physiologically the subject has been treated by many physiologists, and notably most admirably by I)r. Carpenter ; but here the psychological aspect in the special forms indicated is alone brought into prominence.

The phenomena of unconscious thought, indeed, require much greater attention. Not only do they underlie the distinctions between animals and between animals and man, but they must be taken into consideration as explanatory of dreams and of many forms of mental disease. This has been partly dealt with by $\mathrm{Dr}$. Carpenter.

While the later steps of dreams, the visible and pictorial stages, are greatly under the infuence of conscious thought, the early stages are under the influence of unconscious thought. It appears to me quite possible that unconscious thought is not altogether latent in sleep. It is worthy of consideration what is the condition of a wakeful animal, say a dog-whether it is one succession of dreams or a form like delirium.

The recurrence of an error once implanted in the mind, not withstanding our efforts to eliminate or counteract if, is probably due to the tenaciots resistance of unconscious thought, storing up and reproducing the error

Heredity of thought, whether as dealt with by Mr. Francis Galton or by myself in the paper quoted at p. 359 , \&c., may be assigned chiefly to the transmission of the habits of unconscious thought, if we consider more especially the condition of the lower animals.

As my last communication was mentioned in the Daily Telegraph of November 29, and with the assertion that Dr. Carpenter, Mr. C. T. Munro, and myself have provided in unconscious thought a new plea for unaccountability for criminal actions, it is well to remark that the phenomena discussed have no such bearing.

December 20, 1879

HYDE CLARKE

\section{Stags' Horns}

THE disappearance of the antlers of stags, in the Highlands and elsewhere, is to be accounted for by the fact that they are saleable articles; but although they do not assist as entremets at the animal's meal it may happen that they assist-in the form of knife-handles-in the distribution of his venison at our dinners.

When a lad I obtained many antlers of the Fallow Deer from a neighbouring park, the tines of which were sometimes broken but never gnawed or polished by licking.

It would scarcely be surprising that deer should crave for calcareous matter during the rapid development of their antlers, but neither are their tongues adapted for rasping nor their teeth for comminuting hard bones.

Beddington Park

No gillie that $I$ know of has the honour of my acquaintance, and therefore no gillie can know, save indirectly, that I have picked up a horn of the red deer, in a park near Sheffield! I was told at the time by the gardener who accompanied me that these horns were eagerly sought after by the Sheffield knife-makers for the purpose of making bucks' horn knife-liandles.

M. T. M.

\section{A Query}

I HAVE seen somewhere (but I am unable to say where) a statement to the effect that there is some evidence for the supposition that in the crystallising state of matter the forces between molecule and molecule are not directed in the right lines joining the molecules. Can any of your readers throw light on this subject, or give references to sources of information about any other case in which the mutual action of two molecules is not directed in the line joining them? IGNORAMUS

\section{THE ASSERTED ARTIFICIAL PRODUCTION}

$$
\text { OF THE DIAMOND }
$$

\section{PROF. MASKELYNE sends us the following letter} on this subject:-

I should be obliged if you would accord me space in one of your columns in order that I may answer a great number of letters and applications which have pursued me during the past few days on a subject of some little public interest, that subject being the asserted formation of diamonds by a gentleman at Glasgow.

Some ten days ago I had heard nothing whatever of the claim of Mr. Mactear, of the St. Rollox Works, Glasgow, to the artificial production of the diamond.

My name, however, was already in several newspapers as that of a person in whose hands the asserted diarnonds had been placed for a decision as to their true nature. Ultimately a small watch-glass with a few microscopic crystalline particles came into my hands for this purpose from Mr. Warington Smyth, and subsequently a supply came to me direct from Mr. Mactear. I shall proceed to state the results I have obtained from the examination of these.

Out of the first supply I selected by far the largest particle, one about the $\frac{7}{50}$ th of an inch in length, and it may be that I wasted some time in experimenting on this particle, as it might not have been an authentic example 
of the "manufactured diamond," since it differed in some respects from the specimens I have since recelved direct from Mr. Mactear.

The diamond excels all substances in hardness. Its crystals belong to the cubic system, and should not, therefore, present the property of doubly refracting light. Frequently, however, from the influence of strains within the crystal due to inclosed gas bubbles, or other causes, diamonds are not entirely without action on a ray of polarised light sent through them. Finally, the diamond is pure carbon, and, as such, burns entirely away when heated to a sufficiently high temperature in the air, and more vividly so burns, or rather glows away, when heated in oxygen gas.

The specimens I had to experiment upon were too light to possess appreciable weight, too small even to see unless by very good eyesight or with a lens, yet were, nevertheless, sufficiently large to answer the three questions suggested by the above properties.

A few grains of the dust, for such the substance must be termed, were placed between a plate of topaz-a cleavage-face with its fine natural polish-and a polished surface of sapphire, and the two surfaces were carefully "worked" over each other with a view to the production of lines of abrasion from the particles between them. There was no abrasion. Ultimately the particles became bruised into a powder but without scratching even the topaz. They are not diamond.

Secondly, some particles more crystalline in appearance than the rest were mounted on a glass microscope slide and examined in the microscope with polarised light. They asted each and all powerfully in the manner of a birefringent crystal. It seemed even in one or two of them that when they lay on their broadest surface (it can scarcely be called a "crystal-face") a principal section of the crystal was just slightly inclined to a flattish side of it in a manner that suggested its not being a crystal of any of the orthosymmetrical systems. Be that as it may, it is not a diamond.

Finally, I took two of these microscopic particles and exposed them to the intense heat of a table blow-pipe on a bit of platinum foil. They resisted this attempt to burn them. Then, for comparison, they were placed in contact with two little particles of diamond dust exceeding them in size, and the experiment was repeated. The result was that the diamond particles glowed and disappeared, while the little particle from Glasgow was as obstinate and as unacted on as before. I had previously treated the specimen I have alluded to as the first on which I experimented by making a similar attempt in a hard glass tube in a stream of oxygen, and the result was the same. Hence I conclude that the substance supposed to be artificially formed diamond is not diamond and is not carbon, and I feel as confident in the results thus obtained from a few infinitesimal particles that can barely be measured and could only be weighed by an assay balance of the most refined delicacy, as if the experiments had been performed on crystals of appreciable size.

Not content with merely proving what these crystalline particles are not, I made an experiment to determine something about what they are.

Heated on platinum foil several times with ammonium fluoride, they became visibly more minute, and a slight reddish white incrustation was seen on the foil. At the suggestion of Dr. Flight, assistant in this department, a master in the craft of the chemical analyst, these little particles were left for the night in hydrofluoric acid in a platinum capsule. This morning they have disappeared, having become dissolved in the acid.

I have, therefore, no hesitation in declaring $\mathrm{Mr}$. Mactear's "diamonds" not only not to be diamonds at all, but to consist of some crystallised silicate, possibly one resembling an augite, though it would be very rash to assert anything beyond the fact that they consist of a compound of silica, and possibly of more than one such compound.

The problem of the permutation of carbon from its ordinary opaque black condition into that in which it occurs in nature, as the limpid crystal of diamond is still unsolved. That it will be solved no scientific mind can doubt, though the conditions necessary may prove to be very difficult to fulfil. It is possible that carbon, like metallic arsenic, passes directly into the condition of vapour from that of a solid, and that the condition for its sublimation in the form of crystals, or its cooling into crystal diamond from the liquid state, is one involving a combination of high temperature and high pressure present in the depths of the earth's crust, but very difficult to establish in a laboratory experiment.

\section{NEVIL STORY-MASKELYNE}

FURTHER NOTES UPON THE PAPUANS OF $M A C L A Y$ COAST, NEW GUINEA

\section{I.}

HAVING recently received from my friend $M$. von Miklucho Maclay, by way of Singapore, some further notes upon the ethnology of the Papuans of Maclay Coast, in New Guinea, I herewith contribute the following abstract of them to the pages of NATURE, as the periodical in which they were published is not readily accessible to English readers. ${ }^{1}$

The Daily Life of the Papuans.-With regard to the application of pigment to the face and body, the Papuans paint the face with red and black colours, the red being such usually used by the young (those from fifteen to thirty years "malassi"), and the black by those of riper years. The young further use the colouring agents in the form of various devices. On ordinary days they are unpainted, or confine themselves to a ring round the eyes or a line along the nose, which goes to join another running from the temple to the vertex, over the shaved eyebrows. On formal occasions, however, the whole face is smeared with a pigment over which white and black are drawn. Sometimes half of the face is painted black, while the other half is red, which gives a very remarkable appearance. The Tamo, or men over thirty years old, almost never employ the real colour, but substitute black instead. On important occasions the whole head is covered with the pigment; in fact, in certain districts, e.g, "Kar Kar," Dampier Island, where this is abundant, the inhabitants smear the whole body with it, and with such care that it would be readily taken for their natural colour.

The women of Maclay coast are seldom to be seen painted, and, when they are, in not so elaborate a mode as are the men. A description has been already given of the coiffure. Before the arrival of Maclay bamboo knives and fragments of flint were used for the removal of the hair; but during his stay sherds of glass collected in the neighbourhood of his hut were substituted. Another method was also employed for the removal of single hairs by means of a noose made with a stalk of grass, in which the hair was twisted out of its follicle. Although this operation would seem to be a painful one, a Papuan has been seen engaged for three or four hours on this occupation, without a shade of an expression of pain being seen to pass over his features. Although the Papuans of this region are not conversant with the art of tattooing, they are accustomed to burn rows of scars in lines upon the skin. The operation is thus performed:The patient having been placed either upon his back or belly, a red-hot fragment of dry bark is laid

x "Ethnologische Bemerkungen über die Papuas der Maclay-Küste in Neu Guinea-Alltägiges Leben der Papuas" (Fortsetzung). Reprinted from the Naturkundig Tijdschrift voor Nederlindsch Indz̃e, Zevende Serie, Deel vi. p. 294. (Batavia, 1876 .) This abstract may be regarded as a continuation of $t w o$ articles by me upon the same subject, which were published in NATURE, vol. ix. p. 328 , vol. xiv. pp. to $7, x_{3}^{6} .-$ J. C. G. 